\title{
Distributions, compositions, and ecological risk assessment of typical pollutants in surface sediment of Xihe River, China
}

\section{Xun Sun}

Shenyang Aerospace University

\section{Zheng Yan}

Shenyang Aerospace University

Xin Ke ( $\sim$ kex@iae.ac.cn )

Shenyang Aerospace University https://orcid.org/0000-0001-9695-4113

\section{Research Article}

Keywords: Sediment, PAEs , heavy metals, Ecological risk assessment

Posted Date: May 11th, 2022

DOI: https://doi.org/10.21203/rs.3.rs-1161654/v3

License: (c) (1) This work is licensed under a Creative Commons Attribution 4.0 International License.

Read Full License 


\section{Abstract}

Distributions and compositions of six phthalic acid esters (PAEs), eight phenol compounds and seven heavy metals in riverbed sediments of the Xihe River in Shenyang, China. The ecological risks of these typical pollutants were investigated and evaluated based on the risk quotient (RQ) and potential ecological risk index (PERI) methods. The concentrations of total $\sum_{6} \mathrm{PAEs}, \sum_{8}$ phenols and $\sum_{7}$ heavy metals in sediments varied from 92.83 to $293.66 \mu \mathrm{g} / \mathrm{g} \mathrm{dw}, 8.87$ to $83.73 \mu \mathrm{g} / \mathrm{g} \mathrm{dw}$ and 0.46 to $419 \mu \mathrm{g} / \mathrm{g}$ $\mathrm{dw}$. The main pollutants in Xihe River sediments are DEHP, DIBP, phenol, P-methylphenol and Cd. More than half target PAEs and phenol compounds in sediment of the Xihe River exhibited medium or high ecological risk. Cd poses a very high ecological risk to the Xihe River Basin. It is imperative to take some effective measures to reduce the pollution of those contaminants.

\section{Introduction}

Due to Chinese rapid urbanization and industrialization, rivers are increasingly threatened by all kinds of pollutants (Zhao et al., 2018). Riverbed sediments as important sinks and sources for pollutants, the concentration of pollutants in it has a great impact on aquatic organisms and the water environment, even influence the entire ecosystem (Mi et al., 2019; Hu et al., 2020).

Phthalic acid esters (PAEs) are typical plasticizer, whose environmental behavior has attracted considerable attention (Yang et al., 2019; Khalid Muzamil Gani et al., 2016). The US Environmental Protection Agency has identified six congeners, including di-methyl phthalate (DMP), di-ethyl phthalate (DEP), di-n-butyl phthalate (DnBP), di-2-ethylhexyl phthalate (DEHP), di-n-octyl phthalate (DnOP) and butylbenzyl phthalate (BBP), as priority pollutants (Gao et al., 2018; Alkan Nigar et al., 2021). Phenol compounds are important chemical raw materials and are used in large quantities to make phenolic resin, epoxy resin and synthetic fiber (Wang et al., 2020). Phenol compounds have a strong destructive effect on the human body, and can inhibit the central nervous system and have strong toxic, persistent and bioaccumulative effects (Li et al., 2015). Due to the potential biological toxicity of heavy metals, they may cause further adverse effects on human beings through bioaccumulation (Xu et al., 2017). Because of potential risks to humans and the environment of these typical pollutants, the comprehensive evaluations of ecological risks are required.

The Xihe River is 78 kilometers long and flows through the Tiexi District, the most important industrial estate in Shenyang(Liu., 2016). Due to the complete variety and large number of factories around the basin, various types of wastewater are one of the main sources of water for the Xihe River. A variety of pollutants in the basin such as ammonia nitrogen, PCDD and dibenzofurans have been investigated and studied by many people (Ke et al., 2018; Lin et al., 2013; Ke et al., 2019). It is still lack of information on the pollution level of common PAEs, phenol compounds and heavy metals in the river sediment, limited work has reported on the potential risk of these pollutants in the Xihe River. 
In this study, we selected some representative sites as the study area to conduct a risk assessment of heavy metals, PAEs and phenol compounds in Xihe River. The purpose of this study is: (1) to study the distribution and compositions of heavy metals, PAEs, phenols and heavy metals in surface sediments of Xihe River; (2) To evaluate the ecological risk of heavy metals, PAEs and phenol compounds in sediments.

\section{Materials And Methods}

\subsection{Sample collection}

Figure 1 provides sampling locations for this study. Sediment samples were collected from 11 sampling points in Xihe River. The riverine sediments were collected by use of a grab bucket (depth of approximately $0.1 \mathrm{~m}$ ) and then put in a clean stainless steel lunch box. In each sampling point, three duplicate samples were collected and mixed evenly, then transported back to the laboratory and all samples were stored in an icebox stored at $4^{\circ} \mathrm{C}$.

\subsection{Chemical analysis}

Use a centrifuge for 30 minutes $\left(4^{\circ} \mathrm{C} ; 9000 \mathrm{r} / \mathrm{min}\right)$ to extract interstitial water, and store it in a $4^{\circ} \mathrm{C}$ walk-in cooler before collecting samples for chemical analysis. The concentrations of phthalates (PAEs) and phenols were analyzed by Agilent $6890-5973 \mathrm{GC} / \mathrm{MS}$. The sediment samples $(0.5 \mathrm{~g})$ were digested in $20 \mathrm{~mL}$ of a 1:1:2 guaranteed reagent $\mathrm{HNO}_{3}+\mathrm{HClO}_{4}+\mathrm{HF}$ for $10 \mathrm{~h}$, the concentrations of heavy metals were determined by Inductively coupled Plasma Atomic Emission Spectrometry (ICP-AES, Thermo).

\subsection{Risk Assessment}

\subsubsection{Risk quotient}

The risk quotient $(\mathrm{RQ})$ method was used to assess the potential environmental risk of the PAEs and phenols in this work. According to the European technical guidance document (TGD) on risk assessment (EC, 2003; Li et al., 2017; Li et al., 2016*; Zhang et al., 2018; Li et al., 2016**), RQ for PAEs and phenols congeners were calculated from the measured environmental concentration (MEC) divided by the predicted no effect concentration (PNEC), which is described as follows ;

$$
\begin{gathered}
\mathrm{RQ}=\frac{\mathrm{MEC}}{\mathrm{PNEC}} \\
\mathrm{PNEC}_{\text {sed }}=\frac{\mathrm{K}_{\text {susp-water }}}{\mathrm{RHO}_{\text {susp }}} \times \mathrm{PENC}_{\text {water }} \times 1000 \\
\mathrm{~K}_{\text {susp-water }}=\mathrm{F}_{\text {water-susp }}+\mathrm{F}_{\text {solif-susp }} \times \mathrm{F}_{\text {oc-susp }} \times \frac{\mathrm{K}_{\mathrm{oc}}}{1000} \times \mathrm{RHO}_{\text {solid }}
\end{gathered}
$$


where MEC is the measured environmental concentration and PNEC is the predicted no effect on centration. where $\mathrm{PNEC}_{\text {water }}$ values were calculated from the lowest acute toxicity data , $\mathrm{RHO}_{\text {susp }}$ is the density of wet suspended matter, which is $1150 \mathrm{~kg} / \mathrm{m}^{3} ; \mathrm{RHO}_{\text {solid }}$ is the density of the solid phase, which is $2500 \mathrm{~kg} / \mathrm{m}^{3} ; F_{\text {water-susp }}$ is the volume fraction of water in suspension, which is defined as $0.9 \mathrm{~m}^{3} / \mathrm{m}^{3}$; $F_{\text {solid-susp }}$ is the volume fraction of solid in suspension, which is defined as $0.1 \mathrm{~m}^{3} / \mathrm{m}^{3} ; F_{\text {oc-susp }}$ is the mass fraction of organic carbon in suspension, which is assigned as $0.1 \mathrm{~kg} / \mathrm{kg} ; \mathrm{K}_{\mathrm{oc}}$ is the partition coefficient of organic carbon-water $(\mathrm{L} / \mathrm{kg})$.

The PERI (Ke et al.,2017; Ben Mna Haïfa et al.,2021; Islam Md Saiful et al.,2018; Shi et al.,2016; Chai et al.,2017)was used to assess the comprehensive potential ecological risk of heavy metals in sediment and was initially introduced by Hakanson (1980). The potential ecological risk factor of a given metal $\left(\mathrm{E}_{r}^{i}\right)$ is defined as:

$$
\begin{gathered}
E_{r}^{i}=T_{r}^{i} \times \frac{C_{i}}{C_{0}} \\
\mathrm{RI}=\sum_{i=1}^{n} T_{r}^{i} \times \frac{C_{i}}{C_{0}}
\end{gathered}
$$

where $C_{i}$ is the concentration of metal $i$ in sediment, $C_{0}$ is the concentration of the same element in background sediment, $\mathrm{T}_{r}^{i}$ is the biological toxicity factor of an individual element, which was determined for $\mathrm{Cu}=\mathrm{Pb}=5, \mathrm{Zn}=1, \mathrm{Hg}=40, \mathrm{As}=10, \mathrm{Cr}=2$ and $\mathrm{Cd}=30$ (Suresh et al., 2011), $\mathrm{E}_{r}{ }_{\mathrm{i}}$ is the potential ecological risk factor of a single metal, and RI is the comprehensive potential ecological risk index of the metals. The PERI of heavy metals was categorized according to five levels, as shown in Table.1.

\subsection{Quality assurance and Quality control (QA/QC)}

Quality assurance and quality control were assessed in duplicates, with method blanks and standard reference materials. The content of pollutants was determined by three replicates. No target pollutants were detected in the blank control groups. Quantitative analysis of all target compounds was corrected by data of blank test and recovery. The deviations were less than $10 \%$. The quality of the analytical procedures was tested by the recovery measurements on the Chinese national geo-standard (GBW-07333 and GBW-07314). All of the reagents were guaranteed analytical grade or higher. The lab glassware (bottles, tubes, etc.) were pre-cleaned by soaking in $10 \% \mathrm{HNO}_{3}(\mathrm{w} / \mathrm{w})$ for at least 2 days, followed by soaking and rinsing with de-ionized water prior to use (Zhuang et al., 2015)

\section{Results And Discussion}

\subsection{Distribution of PAEs in the Xihe River}


The concentration of $\sum_{6}$ PAEs was shown in Table. 2. In the Xihe River, the mean concentrations of each PAEs is: DEHP $(200.96 \mu \mathrm{g} / \mathrm{g} \mathrm{dw})>$ DNOP $5.88 \mu \mathrm{g} / \mathrm{g} \mathrm{dw})>\operatorname{DiBP}(2.67 \mu \mathrm{g} / \mathrm{g} \mathrm{dw})>\operatorname{DBP}(1.46 \mu \mathrm{g} / \mathrm{g} \mathrm{dw})>$ DMP $(0.20 \mu \mathrm{g} / \mathrm{g} \mathrm{dw})>\operatorname{DEP}(0.15 \mu \mathrm{g} / \mathrm{g} \mathrm{dw})$. DEHP and DNOP were the dominant pollutants in sediments. The maximum concentrations of DEHP and DNOP appear in source of Xihe River (St2; $284.95 \mu \mathrm{g} / \mathrm{g} \mathrm{dw}$ ) and Ganguan (St3; $7.90 \mu \mathrm{g} / \mathrm{g} \mathrm{dw}$ ). The proportion of $\sum_{6}$ PAEs at each sampling point is shown in Figure. 2. According to the chart, it can be seen that the upstream of the fine river is greatly affected by the pollution of phthalates, with the detected content of six phthalates accounting for about $75-92 \%$ of the whole river. Due to the Xihe River mainly flows through Tiexi District, the largest industrial area in Shenyang, all kinds of factories around the river basin are complete, and the Xiannvhe sewage treatment plant, the largest sewage treatment plant in Shenyang, is near its upstream. Therefore, the Xihe River became the largest recipient of industrial effluents and domestic wastewater from Shenyang. In the Dawula (St.9), the concentration of $\sum$ 6PAEs has dropped significantly, among which the main pollutants DEHP and DNOP in the sediments gradually decreased to $87.94 \mu \mathrm{g} / \mathrm{g} \mathrm{dw}$ and $2.93 \mu \mathrm{g} / \mathrm{g} \mathrm{dw}$, which were about one third of the upstream concentration. This may have been caused by the constant dilution of the river

\subsection{Distribution of phenols in the Xihe River}

The concentrations of phenol compounds ( $\sum$ 8phenols) in sediment from the Xihe River were given in Table. 3. The concentration of $\sum 8$ phenols in sediments varied from 8.86 to $83.72 \mu \mathrm{g} / \mathrm{g} \mathrm{dw}$ in the Xihe River. The main pollutants are phenol and p-methylphenol. The proportion of $\sum 8$ phenols was shown in Figure.3. On the upstream of Xihe River, the content of phenol and p-methylphenol is $71.5 \%$ and $80.2 \%$ of the overall sampling point. In addition, the contents of 2, 4-dimethylphenol and 2, 4-di-tert-butylphenol in the upstream area were second only to phenol and p-methyl phenol, accounting for $89.3 \%$ and $81.3 \%$ of the total sampling points, respectively., and the remaining phenols were less than $0.5 \mu \mathrm{g} / \mathrm{g} \mathrm{dw}$. Very similar spatial distribution has been found between the pollution levels of PAEs and phenolic compounds, indicating that both pollutants might be subjected to the same contamination sources. In general, the pollution level in the upstream of Xihe River is much greater than that in the downstream.

\subsection{Distribution of heavy metals in the Xihe River}

The concentration of $\sum_{7}$ heavy metals was shown in Table. 3. In the Xihe River, the mean concentrations of each heavy metals is: $\mathrm{Zn}(333 \mu \mathrm{g} / \mathrm{g} \mathrm{dw})>\mathrm{Cr}(91.68 \mu \mathrm{g} / \mathrm{g} \mathrm{dw})>\mathrm{Cu}(82.43 \mu \mathrm{g} / \mathrm{g} \mathrm{dw})>\mathrm{Pb}(61.66 \mu \mathrm{g} / \mathrm{g}$ $\mathrm{dw})>\mathrm{As}(19.80 \mu \mathrm{g} / \mathrm{g} \mathrm{dw})>\mathrm{Cd}(18.44 \mu \mathrm{g} / \mathrm{g} \mathrm{dw}) \square \mathrm{Hg}(0.68 \mu \mathrm{g} / \mathrm{g} \mathrm{dw})$. From the perspective of pollution, the order of the sampling points is St.4 $\left(\sum_{7}\right.$ heavy metals $\left.=760.63 \mu \mathrm{g} / \mathrm{g}\right)>$ St.10 $\left(\sum_{7}\right.$ heavy metals $=636.80$ $\mu \mathrm{g} / \mathrm{g})>$ St. $8\left(\sum_{7}\right.$ heavy metals $\left.=577.86 \mu \mathrm{g} / \mathrm{g}\right)>$ St.7 $\left(\sum_{7}\right.$ heavy metals $\left.=559.69 \mu \mathrm{g} / \mathrm{g}\right)>$ St. $6\left(\sum_{7}\right.$ heavy metals $=421.02 \mu \mathrm{g} / \mathrm{g}$ ). The distribution ratio of the seven heavy metals at each sampling point is shown in Fig. 4. It can be found that the high proportion of metals in St.4 and st. 10 is due to the presence of many factories for the manufacture of machinery and automobile parts, located along the river and not just in upstream of Xihe River. $\mathrm{Zn}$ is the most important pollutant in Xihe River, followed by $\mathrm{Cr}$ and $\mathrm{Cu}$, which also confirms the reason for the high Content of $\mathrm{Zn}$ and $\mathrm{Cu}$ in the sediment of this basin from the side. 


\subsection{Ecological risk assessment}

The ecological risk assessment of $\sum_{6}$ PAEs and $\sum_{8}$ phenols in sediments was carried out based on the calculated RQ values. In Figs. 5 and 6, among which DEHP and phenol are high-risk in all sampling sites, p-methyl phenol and DIBP are high-risk in three of the four sampling sites. Half of the target PAEs and phenolic compounds in the river have a moderate or high ecological risk to organisms, which means that some effective measures must be taken to reduce the pollution of these pollutants. Among the seven types of heavy metals, $\mathrm{Cd}$ is high-risk at all sampling sites, and the other heavy metals are low-risk. Explain that $\mathrm{Cd}$ is the main pollutant in this area. As a whole, because the potential ecological risk factor of $\mathrm{Cd}$ is too high, the comprehensive potential ecological risk index in the region presents a high risk Therefore, it is necessary to strengthen the detection of $\mathrm{Cd}$ in wastewater and reduce the concentration of $\mathrm{Cd}$ in wastewater to reduce the potential ecological risk of heavy metals in the region as a whole However, Due to the lack of specific biotoxicity number of phenol in sediment and the simple evaluation method in this paper, further research might be needed to establish the real risks of phenolic compounds to benthic organisms.

\section{Conclusion}

The distributions of PAEs, phenol compounds and heavy metals in the Xihe River were investigated and the ecological risk was evaluated in this study. Screen out several pollutants with potential risks to the environment. The results revealed that six PAEs and eight phenols, DEHP, DIBP, phenol and p-methyl phenol were the most abundant pollutants in the Xihe River. The pollution level in the upstream of Xihe River is much higher than that in the downstream. The ecological risk assessment showed that DBP, DEHP, phenol, $\mathrm{p}$-methyl phenol and $\mathrm{Cd}$ in the Xihe River have a high ecological risk to relevant organisms. Thus, only by precisely controlling the above pollutants can the overall ecological risk in the basin be effectively reduced it is imperative to control the discharge of toxic sewage into the rivers so as to reduce the potential risks in the Xihe River.

\section{Declarations}

\section{Ethical Approval}

Before the journal editing process is completed, the paper will not be submitted elsewhere

\section{Consent to Participate}

Xin Ke, Xun Sun and Zheng Yan all agreed to participate.

\section{Consent to Publish}

Xin Ke, Xun Sun and Zheng Yan all agreed to publish.

\section{Authors Contributions}


Xin Ke and Xun Sun conceived and designed experiments. Xun Sun performed experiments, statistical analysis and chemical analysis. Xun Sun wrote manuscript. Xin Ke and Zheng Yan provided technical and editorial assistance.

\section{Funding}

This research was supported by Liaoning Revitalization Talents Program [XLYC1807045], and Shenyang Youth Science, Technology Innovation Talents Support Plan [RC180101]. We thank the Key Laboratory of Clean Energy, Liaoning Province and Shenyang Aerospace University College of Energy and Environment for their scientific research assistance.

-Competing Interests

The authors declare that they have no known competing financial interests or personal relationships that could have appeared to influence the work reported in this paper.

-Availability of data and materials

No additional unpublished data and materials are available.

\section{References}

1. Chai LY, Li H, Yang ZH (2017) Heavy metals and metalloids in the surface sediments of the Xiangjiang River, Hunan, China: distribution, contamination, and ecological risk assessment. ENVIRON SCI POLLUT R 24:874-885

2. EC (2003) Technical Guidance Document on Risk Assessment-Part II. Institute for Health and Consumer Protection, Italy, Ispra

3. Gao DW, Li Z, Wang H (2018) An overview of phthalate acid ester pollution in China over the last decade: Environmental occurrence and human exposure. SCI TOTAL ENVIRON 645:1400-1409

4. Haïfa B, Mna MA, Helali WO (2021) Spatial distribution, contamination assessment and potential ecological risk of some trace metals in the surface sediments of the Gulf of Tunis, North Tunisia.MAR POLLUT BULL,170

5. Hu XY, Yang T, Liu C (2020) Distribution of aromatic amines, phenols, chlorobenzenes, and naphthalenes in the surface sediment of the Dianchi Lake, China. FRONT ENV SCI EN 14:66

6. Khalid Muzamil Gani and Absar Ahmad Kazmi (2016) Comparative assessment of phthalate removal and risk in biological wastewater treatment systems of developing countries and small communities. SCI TOTAL ENVIRON 569-570:661-671

7. Nigar Alkan A, Alkan J, Castro-Jiménez (2021) Environmental occurrence of phthalate and organophosphate esters in sediments across the Gulf of Lion (NW Mediterranean Sea).SCI TOTAL ENVIRON,760 
8. Xu YF, Wu F, Han JG (2017) The current status of heavy metal in lake sediments from China:

Pollution and ecological risk assessment. ECOL EVOL, 7(14)

9. Ke X, Qi YF, Bao QH (2019) Concentrations, Sources, and TEQ of PCDD/Fs in Sediments from the Liaohe River Protected Areas. ARCH ENVIRON CON TOX, 76(2)

10. Ke X, Bao QH, Qi YF (2018) Toxicity assessment of sediments from the Liaohe River Protected Area (China) under the influence of ammonia nitrogen, heavy metals and organic contaminants. ENVIRON TOXICOL PHAR 59:34-42

11. Ke X, Gui SF, Huang H (2017) Ecological risk assessment and source identification for heavy metals in surface sediment from the Liaohe River protected area, China. CHEMOSPHERE, 175

12. Li B, Hu XQ, Liu RX (2015) Occurrence and distribution of phthalic acid esters and phenols in Hun River Watersheds. ENVIRON EARTH SCl, 73(9)

13. Liu YX (2016) Study on the present situation, causes and countermeasures of water environment pollution in Xihe River (Shenyang section). ENVIRONMENTAL PROTECTION AND CIRCULAR ECONOMY, 36(12)

14. Lin CY, He MC, Liu XT (2013) Contamination and ecological risk assessment of toxic trace elements in the Xi River, an urban river of Shenyang city, China. ENVIRON MONIT ASSESS 185:4321-4332

15. Lin CY, He MC, Liu XT (2013) Contamination and ecological risk assessment of toxic trace elements in the Xi River, an urban river of Shenyang city, China. ENVIRON MONIT ASSESS 185:4321-4332

16. Li RL, Liang J, Gong ZB (2016) Occurrence, spatial distribution, historical trend and ecological risk of phthalate esters in the Jiulong River, Southeast China.SCI TOTAL ENVIRON,580

17. Li XH, Yin PH, Zhao L (2016) Phthalate esters in water and surface sediments of the Pearl River Estuary: distribution, ecological, and human health risks. ENVIRON SCI POLLUT R, 23(19)

18. Li B, Liu RX, Gao HJ (2016) Spatial distribution and ecological risk assessment of phthalic acid esters and phenols in surface sediment from urban rivers in Northeast China. ENVIRON POLLUT 219:409-415

19. Md S, Islam MB, Hossain AM (2018) Assessment of heavy metal pollution, distribution and source apportionment in the sediment from Feni River estuary, Bangladesh. Chemosphere 202:25-32

20. Mi LJ, Xie ZY, Zhao Z (2019) Occurrence and spatial distribution of phthalate esters in sediments of the Bohai and Yellow seas. SCI TOTAL ENVIRON 653:792-800

21. Shi CY, Liang M, Feng B (2012) Background values of 39 element series in sediments of water systems in China.EARTH SCIENCE, 41

22. Yang YY, Wang HY, Chang Y (2020) Distributions, compositions, and ecological risk assessment of polycyclic aromatic hydrocarbons and phthalic acid esters in surface sediment of Songhua river, China.MAR POLLUT BULL,152

23. Zhao GM, Ye SY, Yuan HM (2018) Surface sediment properties and heavy metal contamination assessment in river sediments of the Pearl River Delta, China. MAR POLLUT BULL. 136:300-308 
24. Zhang ZM, Zhang HH, Zou YW (2018) Distribution and ecotoxicological state of phthalate esters in the sea-surface microlayer, seawater and sediment of the Bohai Sea and the Yellow Sea. ENVIRON POLLUT 240:235-247

25. Zhuang W, Gao XL (2015) Distributions, sources and ecological risk assessment of arsenic and mercury in the surface sediments of the southwestern coastal Laizhou Bay, Bohai Sea. MAR POLLUT BULL 99(1-2):320-327

\section{Tables}

Table.1. Classification of PERI

\begin{tabular}{llllll} 
Assessment criterion & \multicolumn{2}{c}{ PERI } & & & \\
& Low & Moderate & Considerable & High & Very high \\
\hline & $₫ 40$ & $40-80$ & $80-160$ & $160-320$ & $\geq 320$ \\
\hline RI & $₫ 150$ & $150-300$ & $300-600$ & $\geq 600$ &
\end{tabular}

Table.2. Concentrations of $\sum$ 6PAEs and $\sum$ 8phenol compounds in sediment of the Xihe River $(\mu \mathrm{g} / \mathrm{g} \mathrm{dw})$ 


\begin{tabular}{llll} 
& range & mean & SD \\
\hline DMP & $0.159-0.227$ & 0.198 & 0.025 \\
\hline DEP & $0.085-0.188$ & 0.148 & 0.040 \\
\hline DBP & $0.792-2.132$ & 1.461 & 0.475 \\
\hline DiBP & $0.872-3.746$ & 2.67 & 1.085 \\
\hline DnOP & $2.929-7.903$ & 5.877 & 1.923 \\
\hline DEHP & $87.94-284.945$ & 200.961 & 83.105 \\
\hline$\sum{ }_{6}$ PAES & $92.83-293.662$ & 210.577 & 84.457 \\
\hline phenol & $3.938-28.858$ & 14.88 & 8.944 \\
\hline p-methylphenol & $3.548-51.835$ & 19.679 & 18.860 \\
\hline 2,3-dimethylpheno & $0.049-0.088$ & 0.064 & 0.014 \\
\hline 2,4-dimethylphenol & $0.300-1.815$ & 0.702 & 0.643 \\
\hline 3,5-dimethylphenol & $0.156-0.213$ & 0.184 & 0.027 \\
\hline 2,4,6-trimethylphenol & $0.050-0.086$ & 0.073 & 0.014 \\
\hline 2,4-di-tert-butylphenol & $0.565-0.875$ & 0.755 & 0.117 \\
\hline 2,6-di-tert-butyl-4-ethylphenol & $0.014-0.021$ & 0.017 & 0.003 \\
\hline$\sum{ }_{8}$ Phenols & $8.870-83.726$ & 36.353 & 28.273
\end{tabular}

Table.3. Concentrations of $\sum_{7}$ heavy metals in sediment of the Xihe River $(\mu \mathrm{g} / \mathrm{g} \mathrm{dw})$

\begin{tabular}{llllll} 
& range & mean & SD & TEC & PEC \\
\hline $\mathrm{Cu}$ & $39-118.5$ & 82.43 & 29.33 & 31.6 & 149 \\
\hline $\mathrm{Cd}$ & $9.2-27.6$ & 18.44 & 6.69 & 0.99 & 4.98 \\
\hline $\mathrm{Pb}$ & $12.8-126.8$ & 61.66 & 46.2 & 35.8 & 128 \\
\hline $\mathrm{Cr}$ & $73-101.6$ & 91.68 & 10.27 & 43.4 & 111 \\
\hline $\mathrm{Hg}$ & $0.46-0.83$ & 0.68 & 0.13 & 0.18 & 1.06 \\
\hline $\mathrm{As}$ & $12.9-31.2$ & 19.8 & 6.74 & 9.79 & 33 \\
\hline $\mathrm{Zn}$ & $201-419$ & 333 & 83.34 & 121 & 459.8
\end{tabular}


TEC $=$ threshold effect concentration, PEC = possible effect concentration.

Table.4. Risk quotient (RQ) of $\sum_{6} \mathrm{PAEs}$ and $\sum_{8}$ phenol compounds

\begin{tabular}{lllll} 
& $\mathrm{RQ}(\mathrm{St} 1)$ & $\mathrm{RQ}(\mathrm{St} 2)$ & $\mathrm{RQ}(\mathrm{St} 3)$ & $\mathrm{RQ}(\mathrm{St9})$ \\
\hline $\mathrm{DMP}$ & 0.77 & 0.80 & 0.88 & 0.62 \\
\hline $\mathrm{DEP}$ & 0.52 & 0.24 & 0.49 & 0.40 \\
\hline $\mathrm{DBP}$ & 21.47 & 10.98 & 4.93 & 2.93 \\
\hline DiBP & 29.50 & 25.14 & 22.60 & 6.86 \\
\hline DnOP & 13.64 & 8.88 & 18.29 & 6.78 \\
\hline DEHP & 41.17 & 42.47 & 23.07 & 13.11 \\
\hline phenol & 2885.77 & 1374.53 & 393.81 & 1297.87 \\
\hline p-methylphenol & 95.99 & 21.03 & 6.57 & 22.18 \\
\hline 2,3-dimethylpheno & 0.12 & 0.06 & 0.08 & 0.08 \\
\hline 2,4-dimethylphenol & 0.85 & 0.18 & 0.15 & 0.14 \\
\hline 3,5-dimethylphenol & 0.10 & 0.14 & 0.10 & 0.13 \\
\hline 2,4,6-trimethylphenol & 1.00 & 1.07 & 0.95 & 0.62 \\
\hline 2,4-di-tert-butylphenol & - & - & - & - \\
\hline 2,6-di-tert-butyl-4-ethylphenol & - & - & - & -
\end{tabular}

Table.5. Potential ecological risk factor ${ }^{\left(E_{r}^{i}\right)}$ of $\sum_{7}$ heavy metals 


\begin{tabular}{lllllll} 
& & $(\mathrm{St})$ & $(\mathrm{St6})$ & $(\mathrm{St7})$ & $(\mathrm{St8})$ & $(\mathrm{St10})$ \\
\hline $\mathrm{Cu}$ & 5 & 29.92 & 19.04 & 22.40 & 9.85 & 24.44 \\
\hline $\mathrm{Cd}$ & 30 & 7527.27 & 5318.18 & 2509.09 & 6300.00 & 3490.91 \\
\hline $\mathrm{Pb}$ & 5 & 25.12 & 7.64 & 6.66 & 2.99 & 29.63 \\
\hline $\mathrm{Cr}$ & 2 & 3.33 & 2.52 & 3.06 & 3.51 & 3.41 \\
\hline $\mathrm{Hg}$ & 40 & 0.83 & 0.72 & 0.79 & 0.46 & 0.60 \\
\hline $\mathrm{As}$ & 10 & 25.8 & 21.25 & 15.34 & 14.66 & 35.45 \\
\hline $\mathrm{Zn}$ & 1 & 6.09 & 3.17 & 6.60 & 6.11 & 4.25
\end{tabular}

Figures

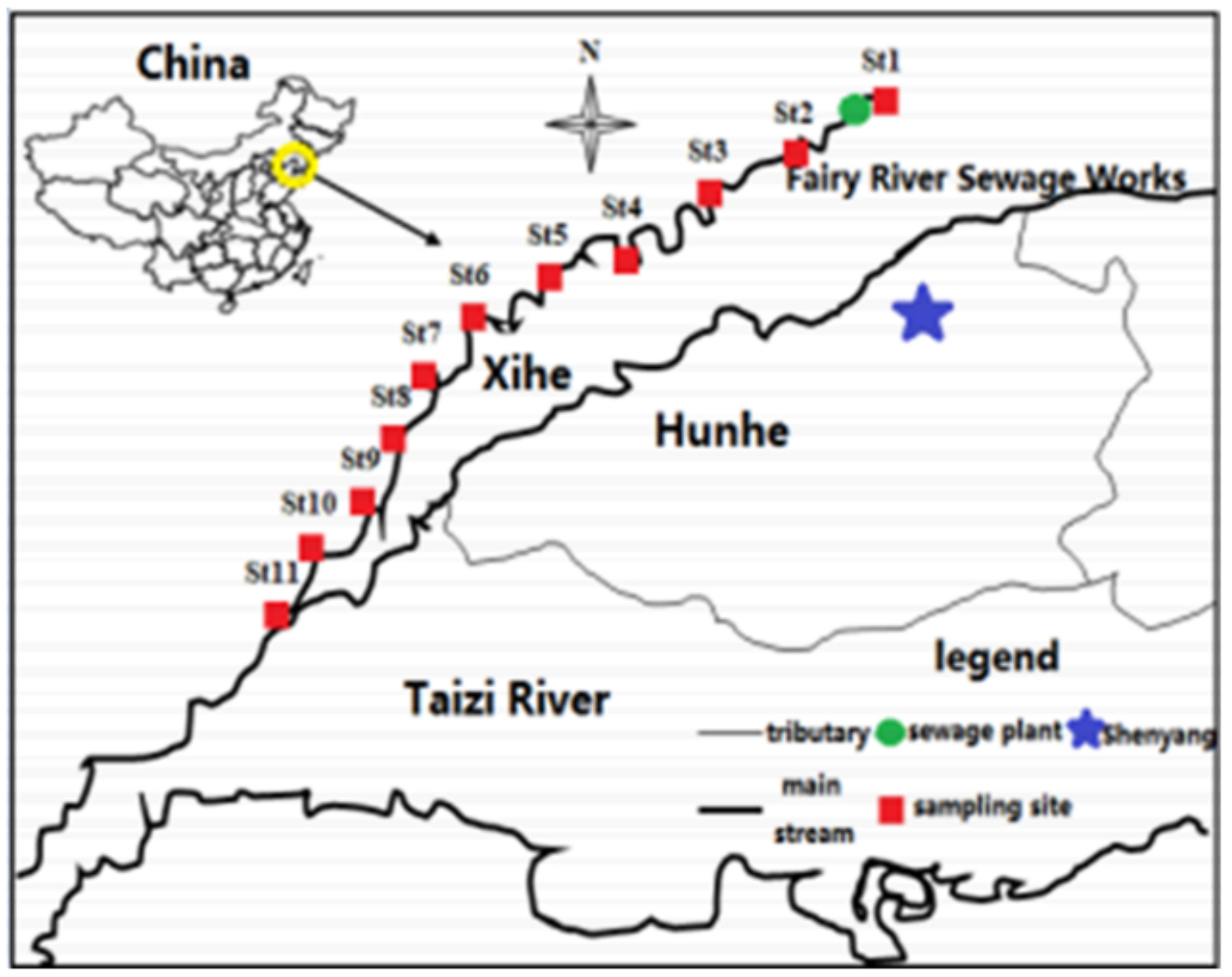

Figure 1 
Sampling sites in Xihe River, China

St.1. Gili Bridge, St.2.source of Xihe River, St.3. Ganguan, St.4. Fuguan, St.5. Aijin,

St.6. Xiaoyu, St.7.Dapan, St.8.Zhangyi, St.9. Dawula, St.10. Qianyu, and St.11. Tutaizi.

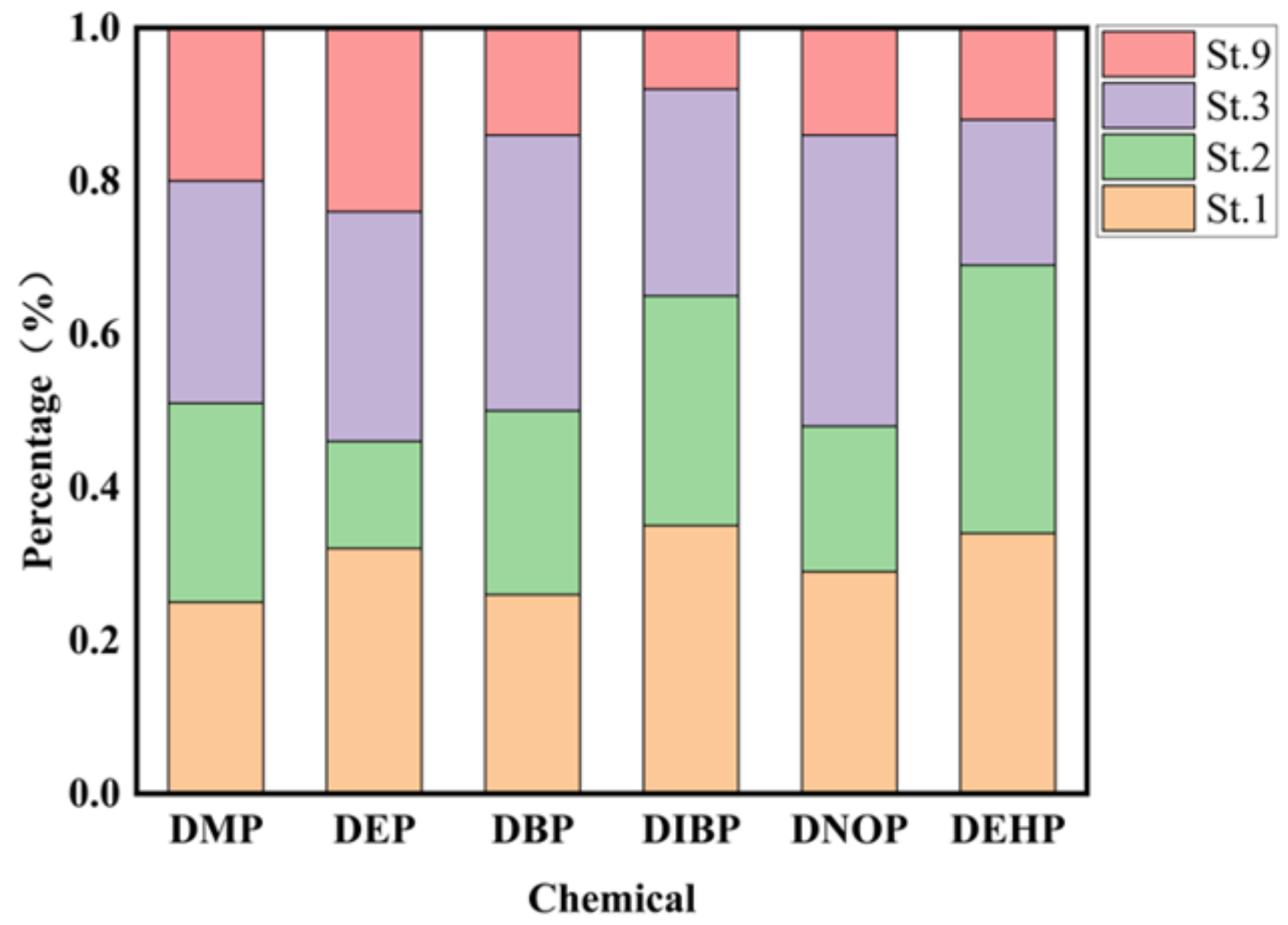

Figure 2

Distributions and compositions of $\sum_{6}$ PAEs in sediment of the Xihe River $(\mu \mathrm{g} / \mathrm{g} \mathrm{dw})$.

$\mathrm{DMP}=$ Dimethyl phthalate, $\mathrm{DEP}=$ Diethyl phthalate, $\mathrm{DBP}=$ Dibutyl phosphate, $\mathrm{DEHP}=$ Di-2-ethylhexyl phthalate, DIBP = Di-iso-butyl phthalate, DNOP = Di-n-octyl phthalate. 


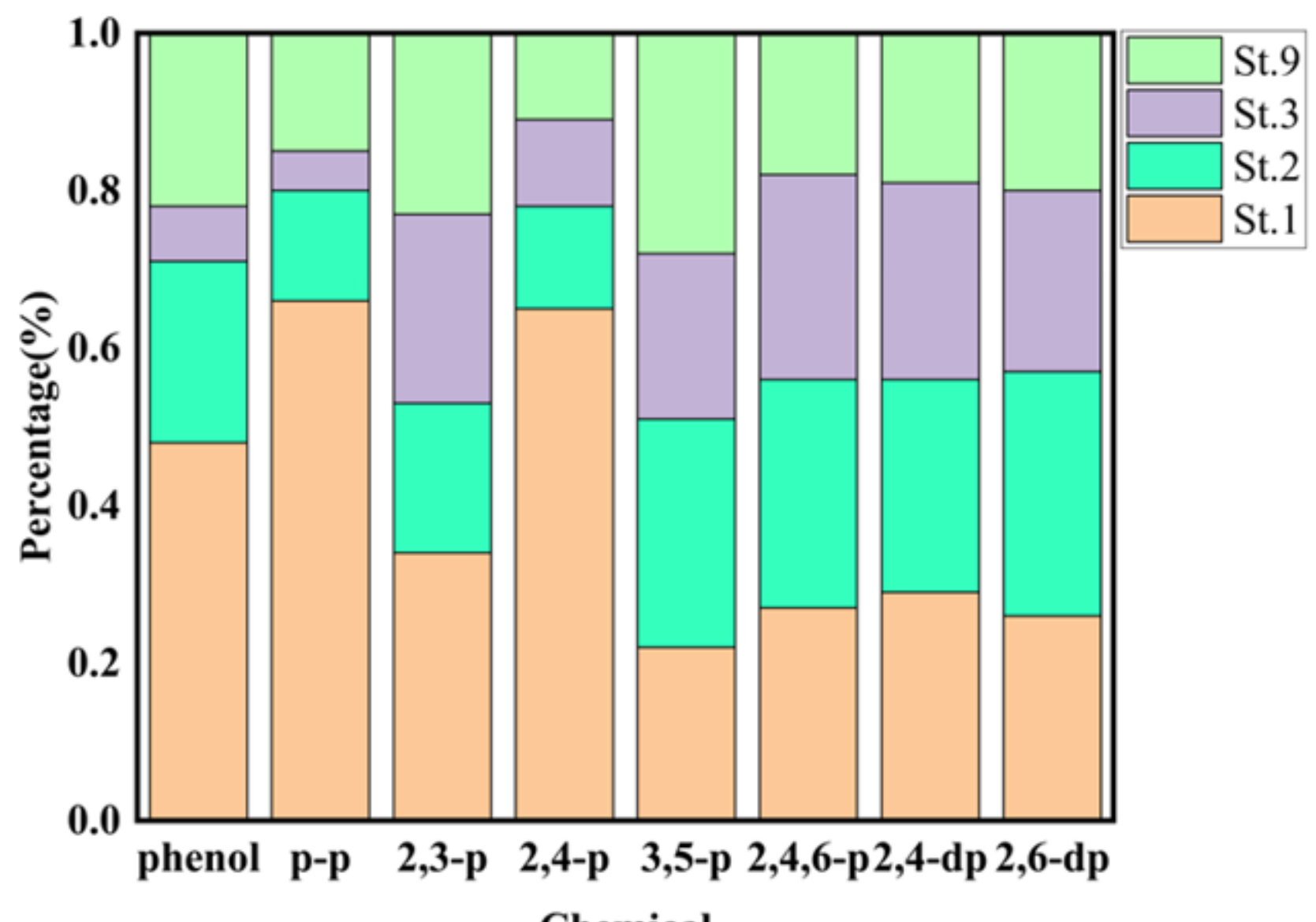

Figure 3

Proportion of $\sum_{8}$ phenols compounds in each sampling dots of the Xihe River sediments $(\mu \mathrm{g} / \mathrm{g} \mathrm{dw})$ $p-p=p$-methylphenol, 2,3-p= 2,3-dimethylphenol, 2,4-p= 2,4-dimethylphenol,

3,5-p= 3,5-dimethylphenol,2,4,6-p= 2,4,6-trimethylphenol,

2,4-dp= 2,4-di-tert-butylphenol,2,6-dp= 2,6-di-tert-butyl-4-ethylphenol. 


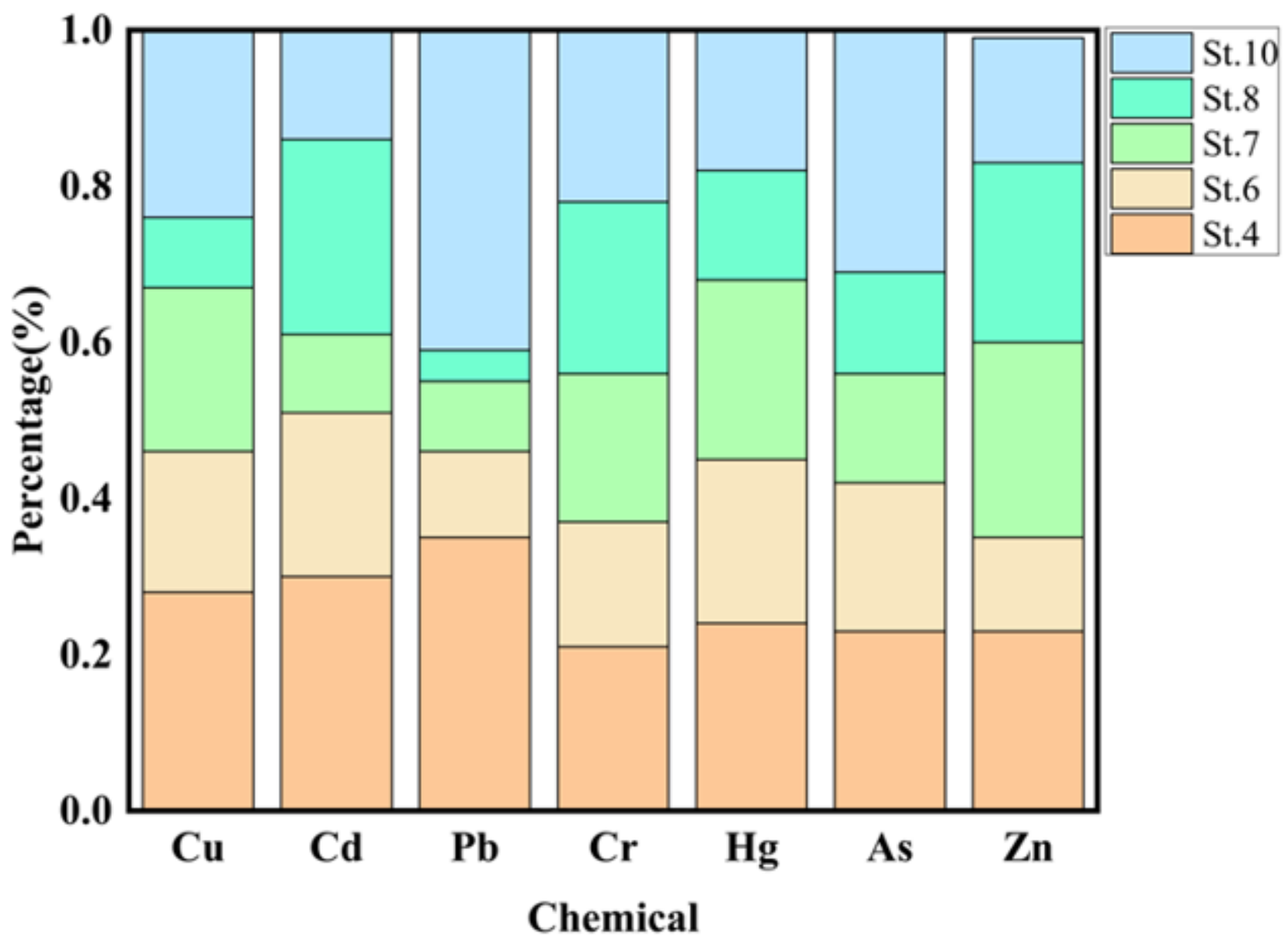

Figure 4

Proportion of $\sum_{7}$ heavy metals in sediment of the Xihe River $(\mu \mathrm{g} / \mathrm{g} \mathrm{dw})$ 


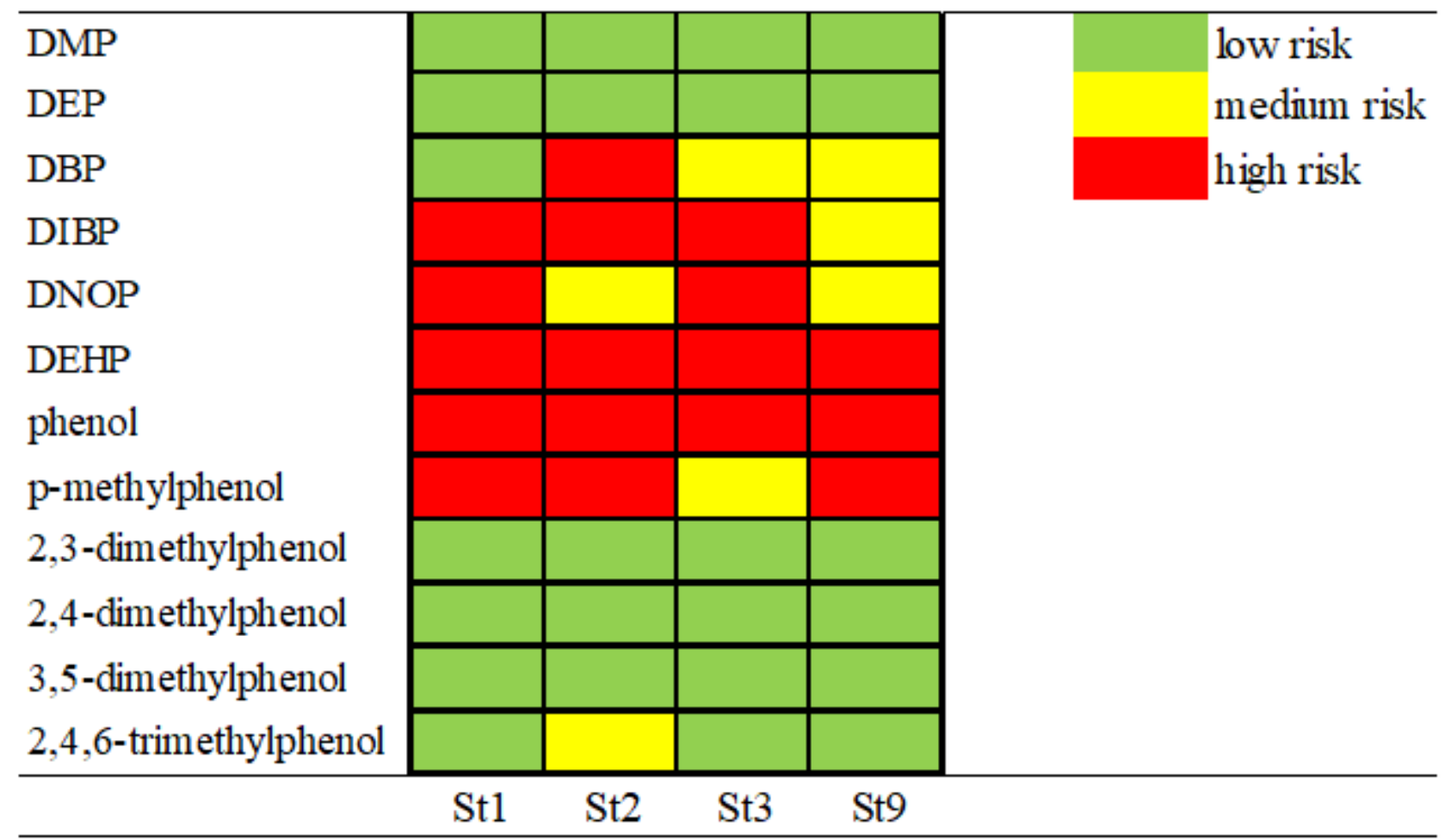

Figure 5

Ecological risk assessment of PAES and phenols in surface sediments of Xihe River

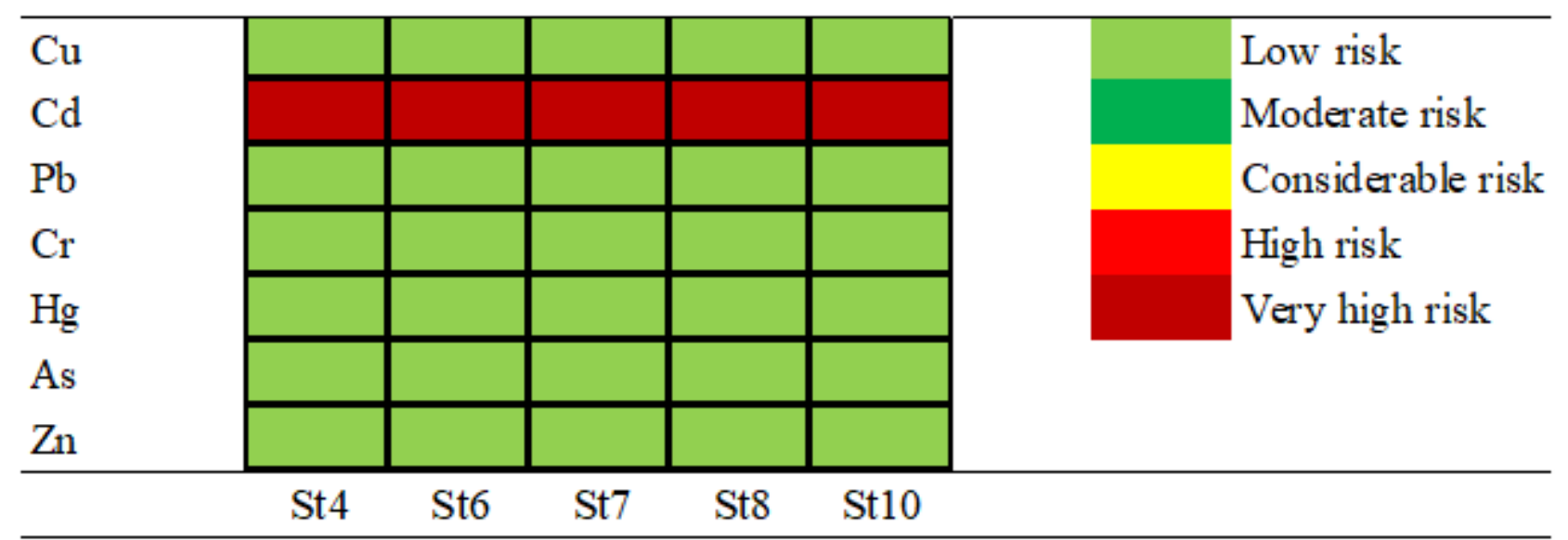

Figure 6

Ecological risk assessment of heavy metals in surface sediments of Xihe River 